\section{Representações do patrimônio na Geografia escolar: o imaginário da festa religiosa cearense no ensino médio}

\begin{abstract}
Resumo: O estudo consistiu-se da associação temática de localidades capazes de formar uma rede de santuários (centros de peregrinação, visitação e difusão do catolicismo) com os aspectos culturais de seu entorno no ensino-aprendizagem da Geografia Escolar. Seu objetivo trabalha o seguinte questionamento: os santuários cearenses projetam uma imagem de bens culturais e ambientais decisivos para a consolidação de uma Educação Patrimonial? O elemento fundamental de tal investigação é sintetizado na festa religiosa. A partir dela se inicia a procura pela interpretação da festa religiosa na prática pedagógica do professor de geografia e na percepção dos discentes acerca do patrimônio cultural que tende a ser marginalizado na organização dos conteúdos curriculares da disciplina geográfica.
\end{abstract}

\section{Representations of heritage in the school Geography: the imaginary of religious party front to practice of the teacher of geography}

\begin{abstract}
The study consisted of the association is themed locales able to form a network of sanctuaries (pilgrimage centers, visitation and dissemination of Catholicism) with the cultural aspects of their environment in the teaching and learning of Geography School. Your goal is working the following question: sanctuaries Ceará project an image of cultural and environmental assets critical to the consolidation of a Heritage Education? The key element of such research is the religious festival. From there begins the search for the interpretation of the religious festival in pedagogical practice of geography teacher and students' perceptions about the cultural heritage that tends to be marginalized in the organization of the curriculum content of the geographical discipline.
\end{abstract}

Christian Dennys Oliveira*

Francisco John Lennon Alves Paixão Lima**

Icla Tamara Alves Carneiro**

* Doutor em Geografia Humana pela Universidade de São Paulo (USP). Professor do Departamento de Geografia da Universidade Federal do Ceará (UFC).

** Licenciado (a) em Geografia pela UFC.

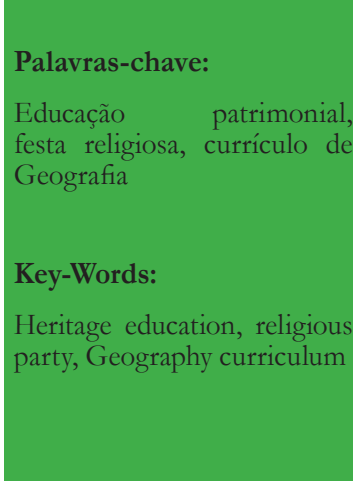




\section{Considerações iniciais}

O estado do Ceará é tradicionalmente marcado por manifestações advindas do catolicismo popular específica ou emersas do calendário litúrgico oficial. E as mudanças da modernidade (crescimento de outras confissões cristãs, secularização) não reduzem a força desta marca na maioria das localidades. Essa amostra devocional está presente nas nove províncias diocesanas do estado. Tais acontecimentos, construção e participação direta da dinâmica socioespacial contemporânea, possuem uma gama de símbolos e signos presentes na experiência do espaço vivido e que acarreta rápidas mudanças no lugar festivo, juntamente com seu entorno. Apesar de toda abrangência das festas religiosas cearenses e da necessidade de sua conservação, devido à importância que tem para cada comunidade, ainda é um tema que vem sendo negligenciado pela ciência geográfica.

Baseado nessas prerrogativas, o estudo se desenvolveu através da investigação da noção patrimonial capturada (mesmo que indiretamente) por discentes e docentes da educação básica, de cada localidade onde ocorrem tais manifestações. Visto que a Educação Patrimonial - com apoio das leituras Estepa; Dominguez; Cuenca (1998), Cuenca (2002), Fontal (2003), Grunberb (2007) e Pelegrini (2011) - se configura como ponto de partida da percepção geográfica frente aos santuários, uma de suas dimensões imateriais interativas (a festa religiosa), tornou-se "fio condutor" do estudo das representações simbólicas sobre o entorno local. Além da visão da educação, enquanto sabedoria e conhecimento popular, de valorização e reconhecimento da cultura e construção da identidade, sua principal marca de renovação está na constituição de lugares simbólicos, ou santuários rituais (OLIVEIRA, 2010), permanentemente estruturados como campo de realização dos saberes coletivos.

Incluímos nesta análise, a possível insurgência de rituais cotidianos que ao serem mais dinamizados tendem a se tornar grandes espetáculos de fé e de modificação da atividade espacial de uma localidade. Para tal foram selecionados dez santuários distribuídos por todo o Ceará, juntamente com dez escolas de ensino médio vizinhas aos mesmos para investigação das transformações turístico-religiosas destes santuários, segundo abordagem fenomenológica das representações culturais na Geografia (REZENDE, 1990). O desafio inicial consistiu em recolher dados e informações para interpretar esse processo, no interior de comunidades escolares, vizinhas e envolvidas mais diretamente relacionadas com a dinâmica desses santuários. Ou seja, constatar qual o vínculo da geografia escolar com a festa religiosa; bem como sua capacidade de potencializar a valorização pedagógica do patrimônio, decodificando a participação escolar neste processo, é possivel na perspectiva discente, principalmente docente. Com esses, o trajeto metodológico do levantamento, de viés qualitativo e uso de procedimentos amostrais e quantitativos, permitiu-nos transformar o questionário em entrevista e visita a escola. Abriu assim duas variáveis diagnósticas: a disponibilidade de transformar um registro formal em conversa informal e a interatividade do professor com a escola. Elemento indispensável à compreensão de que o patrimônio imaterial das festas possa, de algum modo, adentrar no currículo do ensino médio e da Geografia Escolar.

Ainda se esboçou uma aproximação com a perspectiva do filósofo Castor Bartolomé Ruiz, que em seu estudo sobre Os Paradoxos do Imaginário (Ed. UNISINOS,2004), acolhendo uma compreensão de que as representações dos sujeitos escolares implicam a simultaneidade de duas tendências incapazes de síntese. São elas as dimensões lógica e mítica do ensino aprendizagem sobre a questão patrimonial. Absorvendo uma hermenêutica, metodologicamente dinâmica, que o impede de seccionar o imaginário pelo racional ou simbólico exclusivamente, Ruiz tenta "definiri” o imaginário como algo ilimitável, um sem-fundo humano:

Geografia Ensino \& Pesquisa, v. 17, n. 3 p. $127-142$, set./dez. 2013

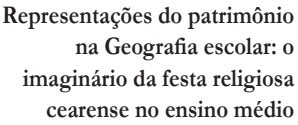
na Geografia escolar: 0 imaginário da festa religiosa cearense no ensino médio

A esse sem-fundo, tragicamente humano, denominamos de imaginário. Sua principal característica é a criação, e paradoxalmente ele possui a possibilidade de encolherse, determinar-se, numa identidade finita e histórica. O imaginário humano é um manancial criativo que (re) sente o mundo de forma criadora; um mistério que emerge de nós na forma de criação (divina) e que transforma o húmus insignificante da natureza em mundo humanizado. (RUIZ, 2004, 23-24). 
Tal aproximação com o manancial criativo corresponde, em certa medida, à recusa do critério político-territorial, engendrado por Iná Elias Castro (2004), para apreender o imaginário geográfico, nos limites do jogo de imagens discursivas. Vimos, conforme a pesquisa detalha adiante, que na Geografia Escolar a microterritorialidade dos espaços vividos que interage com os conceitos espaciais da ciência e justifica a força da dimensão comunicacional na aprendizagem, em um contexto conflituosamente tramado por todo aparado normativo e cibernético (TRIVINHO, 2004). Muito embora tal pontecialidade permaneça disperdiçada no planejamento conteudinal e procedimental da área. E, por essa razão, o imaginário docente cria situações de respostas plausíveis sobre um campo temático contextual, porém não habitual, como o das festas religiosas na vizinhança dos centros devocionais pesquisados.

Para desenvolver os levantamentos empíricos a respeito das localidades, das escolas selecionadas, foi realizada aplicação de questionários ao público discente. Recolheu-se então mais de 600 questionários, considerando que em cada uma das 10 escolas, o contato prévio nos permitiu a aplicação do modelo em duas ou mais turmas de Ensino Médio. A abrangência das informações foi advinda também da execução da entrevista com um docente do ensino médio, em exercício em cada escola participante da pesquisa.

As informações preliminares apontam que a festa religiosa, de âmbito local ou regional pela menção de alguns santuários católicos do estado - faz parte da vivência direta, ainda que descontínua, da maioria dos estudantes das escolas públicas estaduais, O que denota um significativo peso dessa representação cultural em seus cotidianos. O currículo de geografia não contempla qualquer vínculo, mais pontual ou contínuo, com os aspectos das festividades, enquanto patrimônio imaterial; contudo, no tocante ao patrimônio, consegue articular bens históricos urbanos e paisagens naturais como temáticas correlacionadas. O trabalho interdisciplinar para o estudo patrimonial das festas não tem sido exercitado sistematicamente como apoio a essa aproximação dos conteúdos geográficos. Todavia, a lembrança de trabalhos feitos, em anos anteriores, a partir dos festejos da cultura local, favorece a expectativa de um estudo geográfico neste sentido.

O estudo de campo inicia-se pela aplicação de questionários-piloto (maio de 2011) a uma turma de $1^{\circ}$ ano da Escola Estadual Branca Carneiro de Mendonça, no centro de Caucaia (município da Região Metropolitana de Fortaleza); e teve como referência festiva o Santuário de Santa Edwirges, no Bairro do Garrote. A ampliação do levantamento para outras duas turmas apenas confirmou a representatividade do tema no universo de conhecimentos culturais dos adolescentes. Após seis meses (dezembro de 2011) foi possível concluir todo levantamento com os estudantes e desenhar a estratégia de trabalho como os professores de Geografia; que no $1^{\circ}$ semestre de 2012, poderia atender nossa agenda de entrevistas, durante as visitas às escolas.

Lembramos que em cada escola foi necessário respeitar as condições de atendimento e disponibilidade do(a) Professor(a) que nos atendeu, como o tempo para responder ao formulário padrão, interagir com as informações acumuladas dos questionários e das festividades, por intermédio do site do projeto, fazer uma visita às dependências da escola, permitindo-nos uma visualização de sua interatividade com a mesma, receber e ponderar a aplicação da notícia-piloto, a fim de registrar uma experiência de trabalho com a questão da educação patrimonial.

Como resultado desta agenda tão detalhada pudemos constatar, de um lado, a expressiva demonstração de sensibilidade dos docentes para pesquisas que promovem encaminhamentos propositivos, como trabalhos como este: ao explorar os vínculos entre geografia e patrimônio imaterial (cultura popular), indica sugestões de encaminhamentos metodológicos, com sites e notícias. De outro, a necessidade de interpretação mais rigorosa sobre os obstáculos formativos do educador. Embora tais professores visualizem pleno potencial de trabalho com os condicionantes espaciais da festa e da devoção religiosa, muitos bloqueios metodológicos são sugeridos por eles e indicam o vínculo do patrimônio ao aspecto histórico-arquitetônico ou ambiental local. Quase nunca davam a sua discussão em escalas nacional ou internacional; exatamente as que predominam nos conteúdos do ensino médio da área. O que nos incentivou a verificar - em trabalho posterior a ser estruturado para a Geografia acadêmica - os limites curriculares do licenciado sobre a permanência dessa leitura estritamente "local" das questões patrimoniais.

Geografia Ensino \& Pesquisa, v. 17, n.3, p. 127-142, set./dez. 2013.

Oliveira, C. D.; Lima, F. J. L. A. P.; Carneiro, I. T.

ISSN 2236-4994 | 129 


\section{A pesquisa de campo}

Com a aprovação da proposta de pesquisa, em 2010, e a verificação das efetivas condições de confirmação das localidades mais relevantes para debater os valores e representações dos principais festejos religiosos do estado, passamos a desenvolver estratégias para o recolhimento das ideias dos sujeitos escolares. Tal interlocução inspirou-se na elaboração de um formulário de consulta, que servisse de base para elaboração dos questionários discentes e das entrevistas semiestruturadas docentes (MARTINS, 2004; BECKER, 2007).

A progressão dos estudos reflexivos sobre a questão patrimonial, no universo escolar adveio, das leituras do Grupo de Estudos em Representação e Patrimônio (GERP), integrante do Laboratório de Estudos Geoeducacionais do Departamento de Geografia da UFC. Após a formatação metodológica da prática de campo definiu-se dois agrupamentos de escolas/ localidades de encaminhamento de questionários aos discentes e entrevistas aos docentes, enquanto se organizavam as informações sobre as respectivas festas e Santuários conforme a proposta de site do Projeto ${ }^{1}$. O primeiro grupo: Liceu Vila Velha (Fortaleza), Branca Carneiro de Mendonça (Caucaia), Wladimir Roriz (Chorozinho), Paulo Sarazate (Canindé) e Avelino Magalhães (Tabuleiro do Norte); e o segundo grupo: Adauto Bezerra (Fortaleza), Carmosina Ferreira Gomes (Sobral), Coronel Virgílio Távora (Quixadá), Ministro Antônio Coelho (São Benedito), Presidente Geisel (Juazeiro do Norte).

A fase final do levantamento deu-se pela compilação dos resultados e checagem, junto a três dessas escolas, de informações sobre infraestrutura e projeto pedagógicos que não puderam ser consultados nas visitas anteriores. A organização e alimentação das informações na home page do projeto, completou o processo de estudo empírico que aqui detalharemos conforme os dois agrupamentos mencionados.

\section{Resultados da consulta aos discentes}

O questionário aplicado junto aos alunos foi organizado em função de oito questões, mesclando perguntas objetivas e subjetivas e abordando temas relacionados à Geografia escolar e patrimonial. Confeccionamos a formatação dos itens, pensando em categorias de análise e o formato diversificado das questões tendo como apoio duas. Dentre as questões, a abordagem sobre a inserção de temas ligados ao Patrimônio na disciplina de Geografia; sobre

${ }^{1}$ Financiado pela aprovação no edital MCT/CNPq/MEC/ CAPES 02/2010 - Ciências Humanas, Sociais e Ciências Aplicadas.

Geografia Ensino \& Pesquisa, v. 17, n.3 p. 127-142, set./dez. 2013

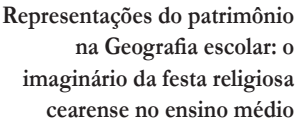
na Geografia escolar: 0 imaginário da festa religiosa cearense no ensino médio patrimônio natural e cultural, este último principalmente religioso; patrimônio cultural nas escolas, dentre outras. As respostas tanto dos alunos quanto dos professores colaboraram para a elaboração de um banco de dados sobre a situação do ensino de Geografia, no que diz respeito à Educação Patrimonial, nos municípios diretamente envolvidos. Esta parte também foi inserida no site $(<$ http//:www.santuario.ufc.br $>)$.

\section{Relato - Questionário Discente (segunda parte)}

O critério de repartição das duas frentes de agrupamento - incluindo esta de 5 escolas e localidades deu-se pela autonomia de agendamento das consultas efetivadas pelos bolsistas do projeto. Assim, não se pode esperar do agrupamento uma correspondência teórica que justifique, por exemplo, porque as duas escolas de Fortaleza permaneceram em agrupamentos distintos.

Em Fortaleza, foram aplicados questionários com 67 alunos, no Liceu Vila Velha, onde apesar da relativa proximidade com o santuário de Nossa Senhora da Assunção, mais da metade dos alunos revelaram não ter relação direta com os festejos relacionados ao mesmo. Apesar de 
existir um alto índice de alunos que já visitaram os santuários de Fortaleza (N.S. de Assunção e de Fátima) e no de Canindé (São Francisco das Chagas), a maioria deles não veem ligação do estudo do santuário na disciplina de Geografia. Admitem apenas que o estudo sobre santuário é importante e assim como as demais escolas é irrisório o número de alunos que pelo menos sabe o que é o IPHAN (Instituto do Patrimônio Histórico Artístico Nacional).

Já na escola Branca Carneiro de Mendonça, localizada no centro de Caucaia, os alunos ficam divididos entre duas manifestações religiosas que acontecem nas proximidades da escola: a do Santuário da Santa Edwiges e a da Nossa Senhora dos Prazeres, padroeira de Caucaia. Ao serem questionados sobre exemplos de patrimônio natural e cultural, as respostas mais incidentes foram a Floresta Amazônica, a Pedra da Galinha Choca, depois os santuários e o Teatro José de Alencar. Acompanhando o perfil também das outras quatro escolas, os alunos do Colégio Branca Carneiro, apesar de significativamente distantes de tais manifestações religiosas, sobretudo sobre em relação à festa, consideram este conhecimento importante. As escolas Paulo Sarazate, em (Canindé) e Avelino Magalhães (Tabuleiro do Norte), dentre as pesquisadas, foram aquelas nas quais os alunos melhor revelaram interação (social e espacial) com eventos festivos relacionados aos respectivos santuários. Ali eles apontaram mais conhecimento acerca dos demais santuários, além de forte participação nos festejos, maior número de visitação e de estudo em relação às temáticas do catolicismo popular.

O Santuário de São Francisco das Chagas, em Canindé, foi o detectado como o polo mais visitado dentre as cinco referidas escolas. Apesar do grande número de alunos que deixaram de responder as perguntas subjetivas do questionário, muitos indicaram como sugestão: a intensificação do estudo patrimonial, questões da religiosidade, mais visitas a locais atrativos no tema; além da inserção de tais conteúdos na disciplina de Geografia e ações complementares às aulas, como palestras, vídeos e debates.

\section{Relato - Questionário Discente (segunda parte)}

Os resultados deste segundo bloco serão iniciados com a escola do município de Juazeiro do Norte, Presidente Geisel. O colégio, que teve o maior contingente de alunos participando da pesquisa, permitiu a totalização e análise de 71 questionários. Seguida desta, a escola Carmosina Ferreira Gomes, localizada em Sobral, que teve participação de 52 alunos. A $1^{\text {a }}$ questão abordou sobre os limites de conhecimento dos alunos sobre o IPHAN (Instituto do Patrimônio Histórico Artístico Nacional) e resultou nos seguintes dados (Figura 1).

Figura 1 - Gráfico: Você sabe ou já ouviu falar no IPHAN (Instituto do Patrimônio Histórico e Artistico Nacional)?

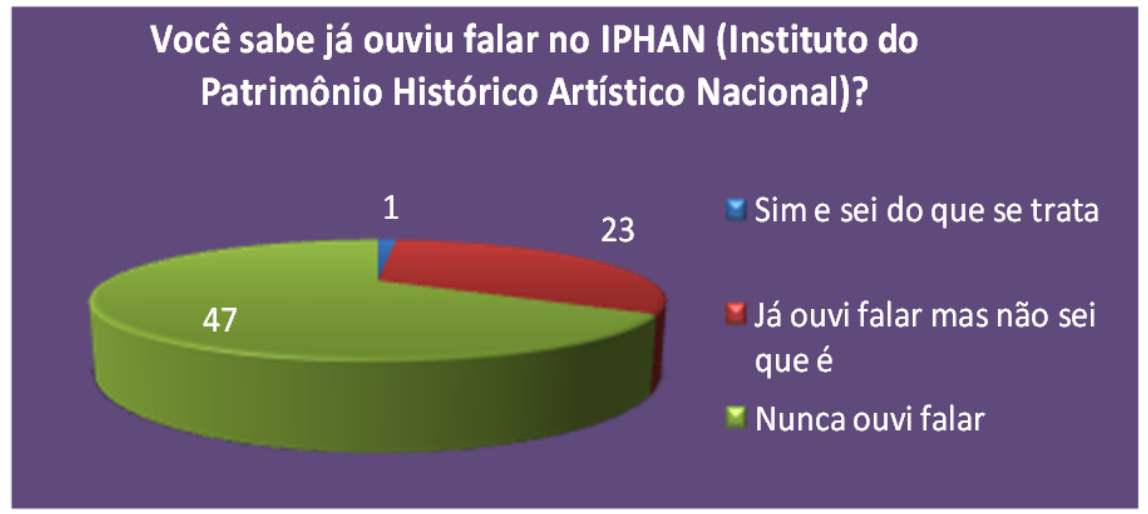

Fonte: elaborado pelos autores, 2012.

Geografia Ensino \& Pesquisa, v. 17, n.3, p. $127-142$, set./dez. 2013.

Oliveira, C. D.; Lima, F. J. L. A. P.; Carneiro, I. T. 
Os dados ilustrados pela Figura 1 apontam que apenas uma resposta, entre todos os estudantes, confirmou ter informações a respeito do IPHAN. O que não surpreende, pois é mais comum alunos conhecerem melhor sobre os bens patrimoniais - mesmo sem essa atribuição de valor - do reconhecerem detalhes sobre quem os gerencia, tendo em vista o convívio cotidiano com os primeiros, e relativa abstração frente às condições de gestão. Já vinte e três alunos que disseram ter ouvido falar não mencionaram de que forma; se na escola ou por outros meios, mas mostram a importância desse instituto a partir desse fato. Essa dimensão de reconhecimento "a distancia" tem muito a ver com a aceitação dos conhecimentos superficiais no entendimento das densidades patrimônio cultural (MATOZZI, 2001, p.103).

Quando indagado sobre bens naturais e culturais (com destaque para a imagética religiosa de Padre Cícero e seus romeiros) do município de Juazeiro do Norte, os alunos expressaram forte conhecimento, fazendo questão de citá-los: Memorial Padre Cícero; Memorial Patativa do Assaré; parque ecológico, Horto, Festa de Santo Antônio, Museu de Padre Cícero, Parque Timbauba, Banco do Nordeste; Geopark Araripe, Basílica de Nossa senhora das Dores, dentre outros. Lembrando a perspectiva de difusão do patrimônio segundo $M^{a}$ Angeles Querol (2010, p.138), no que concerne a interatividade dos objetos paisagísticos para construção da valorização patrimonial, os equipamentos citados corroboram com a ideia de articulação paisagística.

Como os alunos não especificaram quais os tipos de patrimônios que se encaixam na categoria natural ou cultural, não foi possível organizá-los em quadro distintivo. Contudo é perceptível o fato deles realmente conhecem diversos bens patrimoniais, das duas categorias e não somente aqueles que fazem parte direta da vida deles, mas os que são divulgados nacionalmente, pela mídia, comunidade ou livros. Uma das perguntas fundamentais que mostram a percepção dos alunos sobre a interação Geografia-Patrimônio foi: "Você acha que os temas ligados ao Patrimônio (proteção de parques, festas, monumentos) é assunto de Geografia?". As respostas podem ser observadas pela expressividade da Figura 2.

Figura 2 - Gráfico: Você acha que os temas ligados a Patrimônio (proteção de parques, festas, monumentos) é assunto de Geografia?

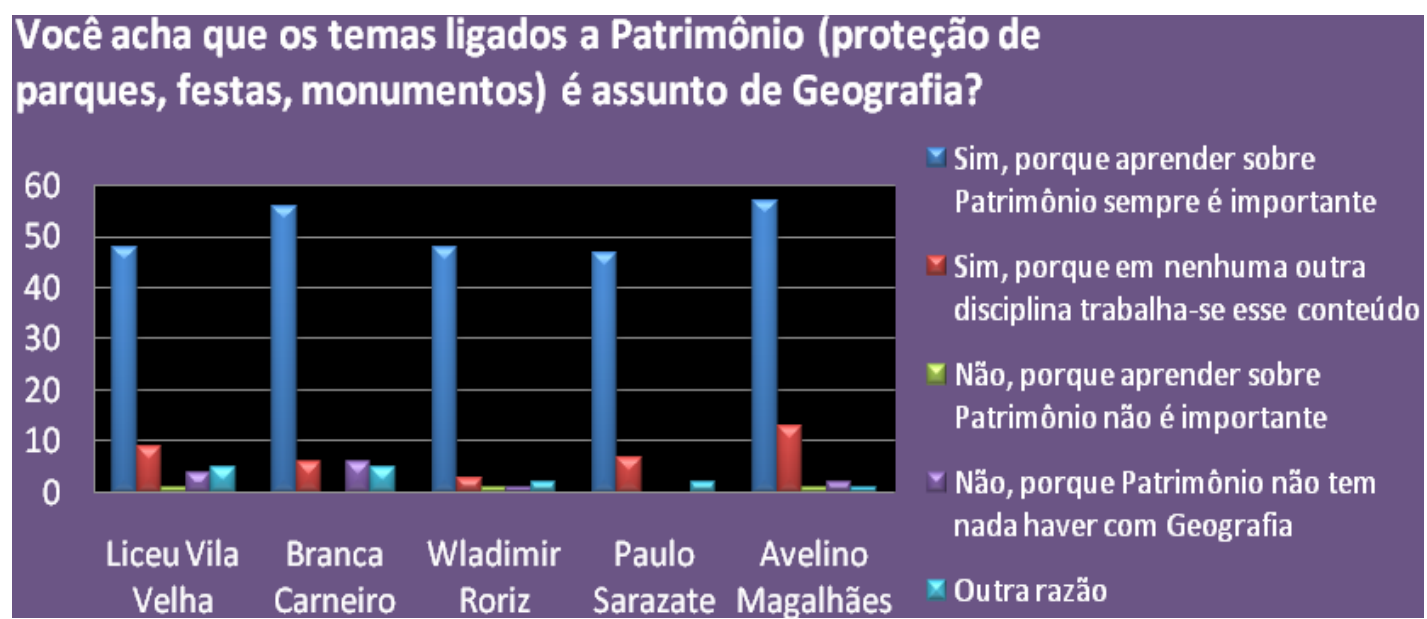

Fonte: elaborado pelos autores, 2012.

Geografia Ensino \& Pesquisa, v. 17, n. 3 p. $127-142$, set./dez. 2013

Representações do patrimônio na Geografia escolar: o imaginário da festa religiosa cearense no ensino médio
A grande maioria respondeu positivamente a importância de se estudar o patrimônio, alegando que é algo útil à suas vidas, permitindo conhecer um pouco mais sobre a história do município. Poucas foram aqueles que negaram a relação Patrimônio/Geografia. E entre as outras razões aparecem respostas do tipo: deve ser estudado em estudos regionais ou só se estuda essa "matéria" no ensino fundamental. Outros disseram que esse é um assunto mais específico da História, porque faz parte do meio em que vivemos. Dentre as respostas sobre o estudo dos patrimônios pelos alunos nas aulas de Geografia, o que mais foi comentado foi a mais 
existência do estudo sobre a Floresta Amazônica como patrimônio natural.

Em contrapartida, estudos sobre monumentos, falésias, sobre a floresta petrificada do Geopark Araripe, dentre tantos outros patrimônios naturais e culturais existentes se mostraram insuficientes dentro de sala de aula. Acreditamos que esse estudo sobre a Floresta Amazônica resulte dos conteúdos de Domínios Morfoclimáticos ou Unidades Geoambientais, pertencentes à disciplina.

Sobre o estudo dos santuários, especialmente do Nordeste, agora mencionando patrimônio cultural religioso, os resultados da $5^{\text {a }}$ questão destacaram a relevância do santuário de N. S. das Dores, em Juazeiro do Norte como o principal inserido nos estudos de Geografia (Figura 3).

Figura 3 - Gráfico: Marque com um “x” qual desses Santuários você...

\section{Marque com um " $x$ " qual desses Santuários você...}

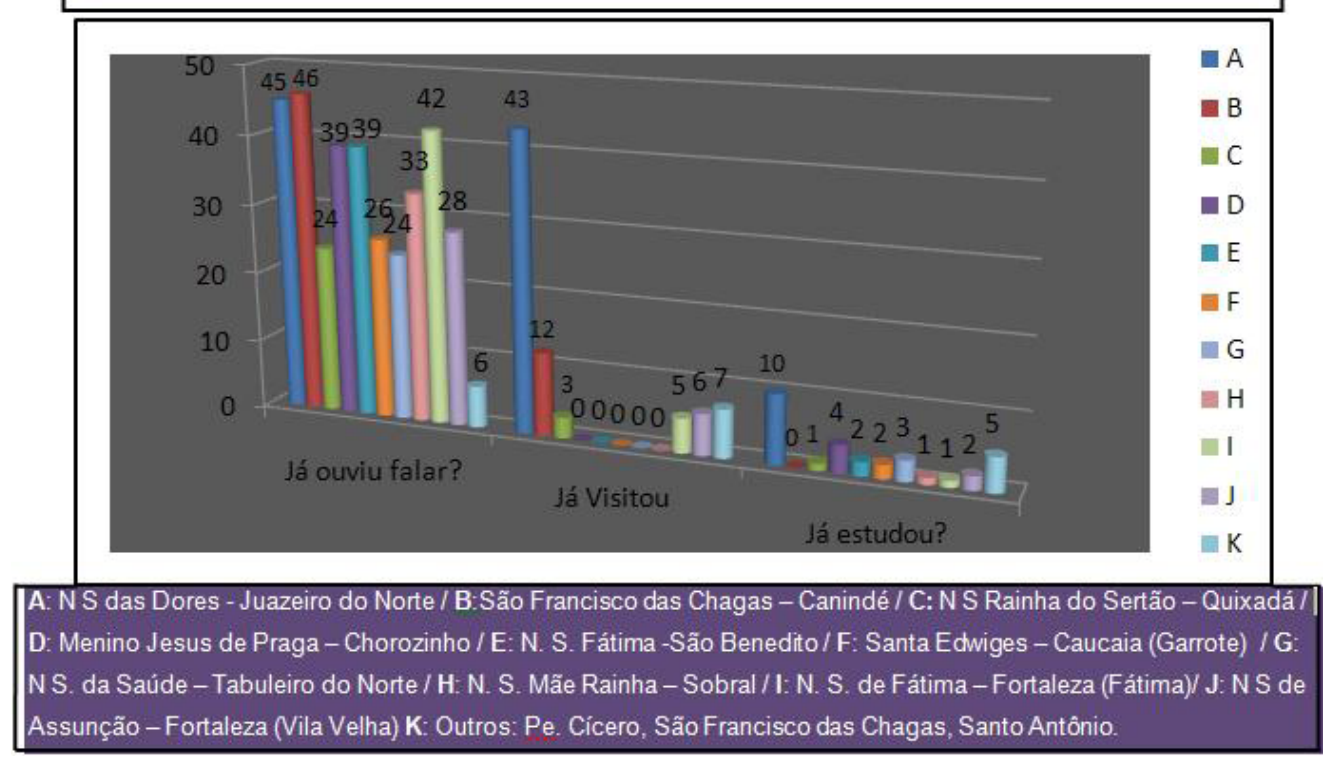

Fonte: elaborado pelos autores, 2012

Não havendo surpresa sobre o destaque do representativo santuário local, chamo à atenção as informações de reconhecimento dos santuários distantes de Juazeiro, (São Francisco das Chagas, Fátima de São Benedito, Rainha do Sertão de Quixadá, etc.), alguns deles sem qualquer menção a visita. Tão pouco eles apontam haver estudado em aula sobre esses santuários, seja na Geografia ou nas demais disciplinas. Muito dos alunos já ouviram falar sobre todos os santuários descrito no gráfico a cima; mas poucos visitaram e/ou estudaram-nos. O que reforça as conexões possibilitadas pelas comunicações, no âmbito das tradições religiosas e na interatividade que os centros de forte peregrinação católica costumam manifestar; como nos permite refletir diferentes trabalhos. (JUNQUEIRA, 2009; FERRARA, 2008)

Contudo, claramente se pode perceber presença de estudos sobre o patrimônio vinculado à religiosidade nas aulas. Pois o padrão de muitas justificativas para respostas indicam que vários alunos estudaram os santuários. O que não quer dizer que não haja participação direta, desses alunos, na festa da santa e padroeira da cidade (uma das datas das grandes peregrinações ao santuário). As respostas se dividiram: 31 alunos disseram que nunca participaram; 23 afirmaram ter participado só uma vez e apenas 17 reconhecem maior frequência no envolvimento com esses festejos.

Ainda no exemplo da escola/santuário de Juazeiro, quando questionados sobre a possibilidade de inserção dos estudos deste santuário nas aulas de Geografia, outra divisão transpareceu entre o "sim" e o "talvez" (Figura 4). O que poderia ser explicado

Geografia Ensino \& Pesquisa, v. 17, n.3, p. 127-142, set./dez. 2013.

Oliveira, C. D.; Lima, F. J. L. A. P.; Carneiro, I. T.

ISSN 2236-4994 133 
em somatória pelo imediato reconhecimento das temáticas culturais ou populacionais na ciência; mas também pela dúvida de como essa abordagem auxiliaria a compreensão da disciplina ou, até, concorreria com outros assuntos já tratados. Caracterizando um exemplo de dificuldades na identificação de temas indispensáveis e possíveis, no âmbito didático das Ciências Humanas e Sociais (ESTEPA; DOMÍNGUEZ; CUENCA, 1998).

Figura 4 - Gráfico: O Santuário de Nossa Senhora das Dores poderia ser estudado nas aulas de Geografia?

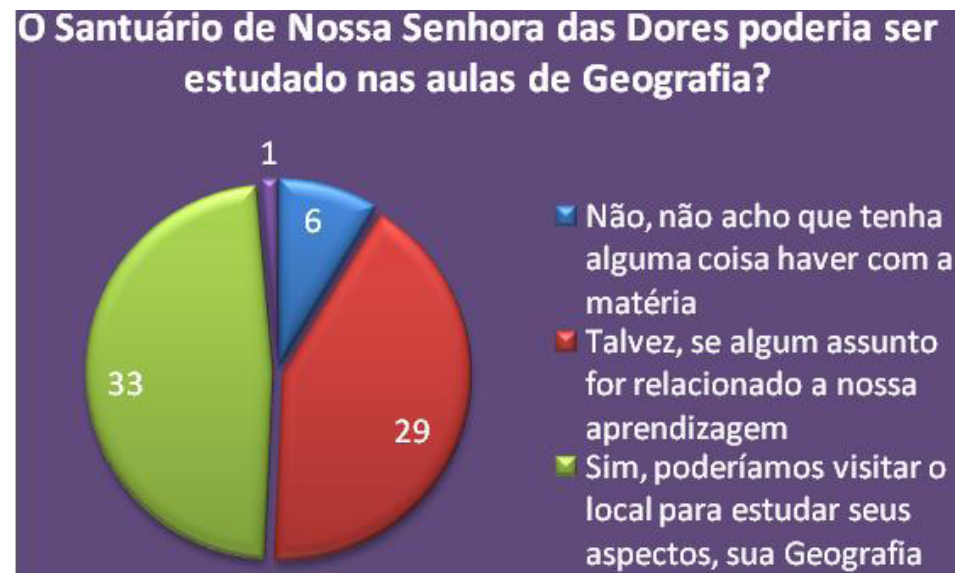

Fonte: elaborado pelos autores, 2012.

A última questão solicitou que os alunos dessem sugestões de como se trabalhar o patrimônio cultural em sala de aula, especialmente nas aulas de Geografia. Dentre as respostas estava à necessidade de se ter professores somente dessa área; trabalhar os pontos regionais na matéria de Estudos Regionais; realizar eventos abordando o Patrimônio como tema, levando os alunos a campo para estimular o conhecimento sobre Patrimônio; Aula de campo, ir para o Geopark Araripe; transporte para visitação, palestras; aula diversificada com visitas de diversos santuários, visitas mensalmente para melhor aprendizagem do local, dentre outras.

O segundo município é o de Sobral. Sua realidade no estudo do patrimônio, assim como em Juazeiro do Norte, é marcada pela lógica de proximidade, em outras palavras, dos equipamentos locais. Os 52 alunos diretamente envolvidos na pesquisa, em maioria conhecem o IPHAN e concordam que os temas ligados ao patrimônio devem ser inseridos nas aulas de Geografia.

Como mostra a Figura 5, a primeira opção: "Sim, porque aprender sobre patrimônio é importante", ficou com 35 votos, mostrando que os alunos conseguem estabelecer essa relação. A opção "Outra razãa" reflete uma inquietação sobre pertencer ou não à temática da Geografia. Os alunos responderam: "porque não acho importante; é mais um assunto especifico da História"; ou "é bom aprender a história de nossa cidade e preservá-la".

Os resultados também apontam que os principais equipamentos estudados nas aulas de Geografia são culturais: às igrejas, os museus e os teatros. Além disso, destacam a cobrança de um posicionamento ético da sociedade frente a esses bens, como " $n a ̃ o$ fazer vandalismo" ou "oprotegerpor sua importância bistórica a comunidade". No que diz respeito ao principal patrimônio religioso visitado e estudado pelos alunos, o Santuário de Nossa Senhora Mãe Rainha (em Sobral). Já o Santuário de

Geografia Ensino \& Pesquisa, v. 17, n.3 p. $127-142$, set./dez. 2013

Representações do patrimônio na Geografia escolar: o imaginário da festa religiosa cearense no ensino médio São Francisco das Chagas, de Canindé-CE, apareceu na segunda colocação. Interessante lembrar aqui que embora o movimento em termos de religiosidade popular mantenha os roteiros de Pe. Cícero, em Juazeiro do Norte como a principal referência das peregrinações e do turismo religioso, no estado, a ideia de "santuário", para eles, vincula aparentemente um apelo mais fixo e institucional; independente dos festejos populares. É por esse raciocínio que percebemos como a distância entre Canindé e Sobral, dá ao Santuário de São Francisco das Chagas, na representação dos estudantes sobralense, forte relevância. 
Figura 5 - Gráfico: Você acha que os temas ligados a Patrimônio (proteção de parques, festas, monumentos) é assunto de Geografia?

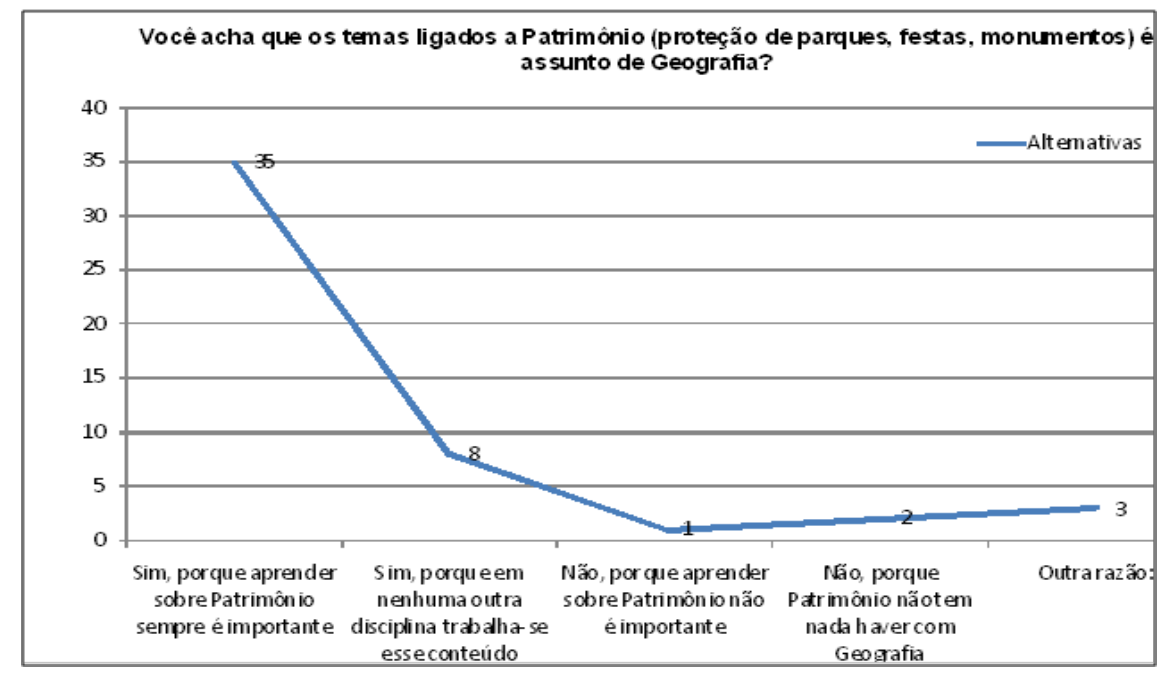

Fonte: elaborado pelos autores, 2012

Quando questionados se o Santuário da Mãe Rainha poderia ser estudado nas aulas de Geografia, a maioria (23 alunos) gostaria sim de estudá-lo, mas de uma forma mais dinâmica, na perspectiva do campo (Gráfico 6).

Figura 6 - Gráfico: O Santuário da Mãe Rainha poderia ser estudado nas aulas de Geografia?

\section{O Santuário da Mãe Rainha poderia ser estudado nas aulas de Geografia?}

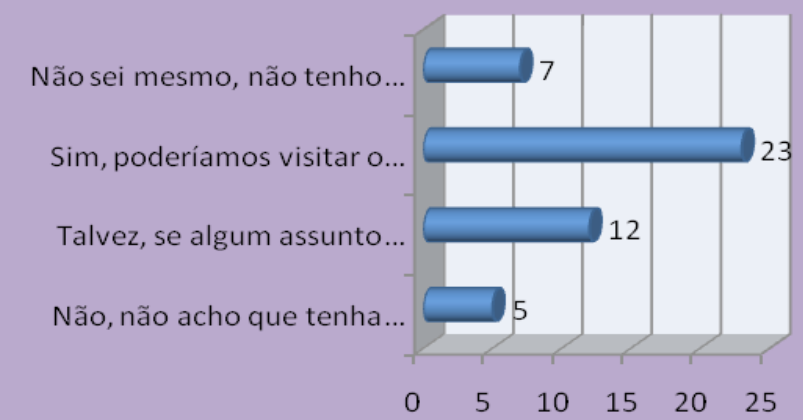

Fonte: elaborado pelos autores, 2012.

Para esse campo, os alunos deram a sugestão para que projetos e estudantes universitários pudessem trabalhar junto a eles, proporcionando visitas a campo, palestras, debates sobre vídeos, etc. De forma geral, as cinco escolas trabalhadas, nesse agrupamento, demonstraram que os estudos sobre patrimônio estão presentes nas aulas de Geografia, mas muito ainda timidamente. Também reflete a amplitude de maior vínculo com o a dimensão histórico-cultural do patrimônio, considerando o peso simbólico específico das como cidades- santuários; que como caso de Canindé, irradiam fortes vínculos com a polarização histórica da ocupação regional (CLAVAL, 1999).

As dificuldades de reconhecimento pelo discente a cerca do IPHAN (Instituto do Patrimônio Histórico Artístico Nacional), mostraram-se a distância da sigla e do papel estratégico que o Instituto possui estudantes nunca ouvi. Se de um lado isso denota um alerta para que a aproximação entre a Geografia e a questão patrimonial não perca o foco institucional, de outro, aponta um questionamento indispensável: até que ponto a leitura espacial de bens patrimoniais não permanece muito restrita uma visão histórica muito restritiva?

Geografia Ensino \& Pesquisa, v. 17, n.3, p. 127-142, set./dez. 2013.

Oliveira, C. D.; Lima, F. J. L. A. P.; Carneiro, I. T.

ISSN 2236-4994 | 135 


\section{Relato - Entrevista Docente (primeira parte)}

Primeiramente, retomemos a realização das entrevistas docentes no primeiro grupo de escolas: Liceu Vila Velha (Fortaleza), Branca Carneiro de Mendonça (Caucaia), Wladimir Roriz (Chorozinho), Paulo Sarazate (Canindé) e Avelino Magalhães (Tabuleiro do Norte). Para fazer uma síntese de informações gerais sobre a postura dos docentes acerca das questões patrimoniais interligadas ao sentido religioso, foi entrevistado um professor de cada escola. De caráter semiestruturado, a entrevista se desenvolveu com o registro dos principais pontos levantados por cada docente e da percepção do mesmo em relação à temática. Ao final da entrevista foi proposto a cada professor que realizasse uma sondagem do conhecimento (atividade simples) dos alunos de uma turma do ensino médio, utilizando uma notícia veiculada no jornal sobre a Festa do Pau da Bandeira, em Barbalha, que passa pelo processo de registro.

De imediato, o único professor que se opôs foi o do Liceu Vila Velha alegando não haver tempo no calendário letivo para esse tipo de atividade. Todos os docentes citaram o tema urbanização, um processo de transformação do espaço, como possível tema para abordar a questão patrimonial em sala de aula. Também houve a associação com a Geografia econômica e a exemplo das professoras do Avelino Magalhães (Tabuleiro do Norte) e do Paulo Sarazate (Canindé), a ligação direta da temática com a questão ambiental.

Referiram-se a noção geral patrimonial como algo que se deve conhecer e conservar, a fim de resguardar bens, resultantes de uma construção social, para as gerações futuras. Ao serem questionados sobre exemplos de festas religiosas em escala local, regional e nacional, houve uma correspondência de respostas principalmente referente à festa de Nossa Senhora Aparecida, em São Paulo, de dimensão nacional. Localmente foram mais citadas as festas equivalentes ao lugar da pesquisa, ou seja, das festas já pesquisadas, que em termos regionais ganharam destaque a festa do Padre Cícero em Juazeiro do Norte, a de São Francisco das Chagas em Canindé e as Festas Juninas como um todo.

As festas citadas foram avaliadas pelos entrevistados como passíveis de registro, enquanto patrimônio imaterial. Mas quando questionado sobre qual poderia ser um Patrimônio da Humanidade, o docente da Escola Branca Carneiro foi o único a apontar a festa da N. S.

${ }^{2} \mathrm{Na}$ entrevista da escola Paulo Sarazate foi possível verificar que o Projeto pedagógico inclui atividades culturais diretamente vinculadas aos dois grandes festejos do ano: As festas Juninas e as Romarias da novena de São Francisco (final de setembro e início de outubro). Em ambos, nos dias mais movimentados, a escola fica fechada e o período preparatório, envolvendo os fins de semana, é considerado letivo para compensar o calendário.

Geografia Ensino \& Pesquisa, v. 17, n.3 p. 127-142, set./dez. 2013

Representações do patrimônio na Geografia escolar: o imaginário da festa religiosa cearense no ensino médio Aparecida, justificado por sua projeção e grandeza. Já os demais justificaram o posicionamento contrário a essa possibilidade ou pela limitação da língua portuguesa e da própria religião frente a outros países ou porque tais festas já possuem referências similares em outras partes do mundo.

No que diz respeito aos obstáculos à realização de trabalhos pedagógicos com patrimônio imaterial (festas), nas respectivas escolas, apareceram como resposta: a falta de material de apoio sobre o tema (âmbito escolar), o desinteresse de discente para com tal temática, e a orientação religiosa diversa de pais e alunos. A docente da escola de Canindé foi a única a enfatizar o apoio às temáticas culturais por parte da escola e destacou que o cotidiano escolar se altera conforme a vida religiosa da cidade ${ }^{2}$. Ela e mais dois professores afirmaram já terem utilizados os santuários como parte de explicações referentes aos conteúdos dentro da sala de aula.

\section{Relato - Entrevista Docente (segunda parte)}

Nesta parte é enfatizada as concepções de quatro deles, conforme as entrevistas em Fortaleza, Quixadá, São Benedito e Sobral. De forma geral, abrangendo todas as entrevistas, os templos religiosos do Ceará foram considerados patrimônios culturais e pertencentes à ótica da Educação Patrimonial. Uma indicação já considerada padrão pelos estudiosos das representações sociais (SÁ, 2002) e da dimensão espaço temporal das festas (DI MEO, 2001), quando conferem aos símbolos materiais um papel mais imediato e eficiente no reconhecimento do valor patrimonial. Neste sentido, as festas, embora mais envolventes, demandam maior abstração para ganhar tal status.

Quando a percepção cultural ganha enfoque conflituoso o que potencializa a valorização cultural pela eminência da perda ou da falta - semelhante ao sentimento de distância relativa 
enfatizada por Dardel (2011) ao pensar o sentimento do migrante - a abstração deixa de ser tão problemática. Dentre os pontos mais ressaltados nessa direção encontramos: a cultura Afrobrasileira, o açude Cedro (Quixadá), a questão da ocupação urbana e seus conflitos, o turismo, etc.

Indagados sobre a utilização da noção de Patrimônio Natural e Cultural na disciplina, os professores falaram da prática de campo, relatando: o espaço cultural do centro de Fortaleza, os bens materiais derivados da humanização da paisagem, os inselbergs (os lacólitos, maciços residuais concentrados na depressão sertaneja), a utilização de mapas, santuários ecológicos e religiosos, dentre outros. Das festas religiosas em amplitude de envolvimento ou conhecem, os maiores destaques confirmaram as menções feitas pelos alunos: Nossa Senhora de Fátima como sendo de caráter local, São Francisco das Chagas e Padre Cícero em âmbito regional. Em termos nacionais, a mídia e a hierarquia do Santuário de Aparecida (SP) voltaram a se manifestar.

Muitos dos professores gostariam de abordar assuntos sobre esses santuários em suas aulas. Ou mesmo fazer aula de campo com os alunos tratando de temas ligados ao artesanato, processos históricos de ocupação e formas de manutenção e transformação cultural dos festejos. Sinalizando para uma dinamismo na leitura das paisagens culturais em busca de uma inovação significativa de suas práticas (ESPINA BARRIO; MOTTA; GOMES, 2005), contudo alguns relataram empecilhos à produção dessas atividades: o cronograma do terceiro ano letivo do ensino médio que é focado particularmente no vestibular, o que não permite ou dá margens a contemplação desse temário, o próprio desconhecimento dos alunos sobre esse assunto, a diversidade religiosa dos alunos nas salas (alunos e alunas evangélicas, ateus, católicas, etc.) e a dificuldade de conciliar o ano letivo ao calendário da festa religiosa.

Em suma, percebeu-se que os estudos envolvendo o patrimônio cultural (que inclui elementos de ordem natural) se faz presente nas aulas de Geografia, mas que ainda existem barreiras à prática desse temário na organização curricular da disciplina. Persiste a tentativa, ainda tímida, de se introduzir esses estudos. Outro ponto relevante é a consciência dos alunos sobre patrimônio, mesmo com uma fragilização pelo tímido estudo sobre patrimônio na sala de aula.

\section{Interpretações}

Avançando na discussão, a partir dessa leitura docente dos aspectos patrimoniais da festa religiosa no currículo, tememos as seguintes inflexões. Inicialmente traçamos duas linhas de partida inspiradas nos alertas epistemológicos de Bachelard (2008), para não cairmos na "ilusão científica" de que: a) a pobreza/miséria sertaneja do estado expliquem por si a relevância das manifestações religiosas, sobretudo aquelas vinculadas aos catolicismos popular e mariano; e b) a de um projeto curricular explicitamente cultural justifique a frágil preocupação cearense com as questões patrimoniais dos bens tangíveis ou intangíveis. Recusando esse dois polos sedutores por hipótese, podemos partir da seguinte questão: Em que medida a dinâmica educacional das escolas cearenses precisam articular seus projetos e programações à realidade cíclica dos eventos religiosos? Lembramos ainda que o Ceará está contido em um contexto mais amplo, que mostra a região nordeste do país como a mais católica; e o próprio Brasil, oficialmente laico, mas tendo de responder em suas políticas públicas a uma população (cerca de 3/5) declaradamente católica! Foram raciocínios que permaneceram latentes na pesquisa influenciando os recortes amostrais. Daí a necessidade de se estabelecer uma sondagem, a priori, com o contexto social das localidades; depois com a própria comunidade escolar, que está geograficamente mais próxima aos santuários religiosos trabalhados. Só assim foi possível confirmar a manutenção das escolas de ensino médio, nas quais o trabalho efetivou-se.

O sentido de trabalhar primeiramente a percepção dos alunos é proveniente da leitura fenomenológico-educacional proposta por Antonio Muniz Rezende (1990), que se traduziria por um sentido patrimonial para o espaço cultural de sua aprendizagem. Pois, a fenomenologia

Geografia Ensino \& Pesquisa, v. 17, n.3, p. $127-142$, set./dez. 2013.

Oliveira, C. D.; Lima, F. J. L. A. P.; Carneiro, I. T.

ISSN 2236-4994 
consiste em uma perspectiva de estudo dos fenômenos apresentados à consciência dos sujeitos (professores), pela reapresentação dos saberes intersubjetivos: a aprendizagem discente. Os coletivos que fazem parte direta ou indiretamente desta dinâmica - professore e alunos - podem assim ler o mundo patrimonial da festa como conteúdo geográfico. Como explica Oliveira:

\footnotetext{
A leitura fenomenológica é uma descrição infinita do fenômeno, de maneira a contemplar seus mais diversos ângulos. A descrição é um procedimento por demais conhecido no universo dos estudos Geográficos. Mas, ao contrário da recomendação fenomenológica, ela costuma ser feita, exclusivamente, na direção objeto $=>$ sujeito, conforme a herança positivista (OLIVEIRA, 2010, p. 50).
}

Como já apontado nos resultados vimos que os discentes se identificam como pouco participantes da festa, excetuando a escola de Canindé. Apesar desse quadro, observamos também que a mesma maioria admite a importância do estudo do santuário, enquanto conteúdo da disciplina geográfica e em relação à educação patrimonial.

O quadro geral que se tem de tais escolas é que os alunos, em número majoritário, não tem conhecimento sobre as questões patrimoniais. Detectamos essa informação através do número de alunos que responderam demonstrando pouco conhecimento sobre tal tema, como em relação aos que deixaram em branco.

A razão da pesquisa gira em torno do que se tem enquanto representação festiva de um perfil devocional, na contemporaneidade das novas práticas e modos de adesão espiritual (HERVIEULEGER, 2008). A festa religiosa é uma expressão popular massiva, que modifica o espaço, que mostra expressão e que está identificada enquanto prática de cultura. Ao se questionar a interação dos alunos nesta festa chama atenção para as questões voltadas à construção da identidade, dos valores da memória de tal evento e da amplitude que o mesmo tem ou pode vir a ter. Tal manifestação, ora polarizada entre o sacro e o profano (ROSENDHAL, 1996) ora reconhecida em sua ambiguidade latente (AMARAL, 2000) também é uma representação e construção coletiva dotada de significados simbólicos. Fazem parte da vida de indivíduos que permanecem relativamente a ser "ignorados" nos currículos generalistas das disciplinas escolares.

A festa figura também entre a potencialidade de transformação da memória em patrimônio imaterial (RAUTENBERG, 2003) traduzindo as metas e valores de uma pósmodernidade positiva em escala internacional, conforme Bertrand Cabral.

Entendem-se como "patrimônio cultural imaterial" as práticas, representações, expressões, conhecimentos e aptidões - bem como os instrumentos, objetos, artefactos e espaços culturais que lhes estão associados - que os grupos e, sendo o caso, os indivíduos reconheçam como fazendo parte integrante do seu patrimônio cultural (CABRAL, 98, p. 17).

A noção de patrimônio costuma ser demarcada como projeção do sentido romano patrimoniun na atualidade complexa, ampliando sua simbologia e seus litígios (POULOT, 2009). Com o agravo de que em relação ao patrimônio imaterial, o principal desta preservação encontra-se na prática coletiva, seja tradicional ou moderna. Esta sentença é destacadamente polêmica, pois fixa nos indivíduos a manutenção e perpetuação do patrimônio imaterial, enquanto sentido de identidade, de memória, de história. Mas patrimônio é vivo; não é

Geografia Ensino \& Pesquisa, v. 17, n. 3 p. $127-142$, set./dez. 2013

Representações do patrimônio na Geografia escolar: o imaginário da festa religiosa cearense no ensino médio imutável e nem estável, principalmente quando se trata de um bem diretamente vinculado à temporalidade das manifestações e saberes humanos. E tais "saberes" muitas vezes compreendidos na idealização bergsoniana da "duração", tende a ser veiculado, exibido e ritualizado na contestação bachelardiana do "instante" (PAIVA, 2005). Sua versão no instante seguinte apresenta mudanças tão vitais quanto imprevisíveis. Por isso a salvaguarda desses bens é pleiteada como uma ética de conservação identitária. Salvaguardar quer dizer institucionalizar para conservar (em determinadas circunstâncias compreendida na tônica do preservar). 
O órgão maior responsável por esse registro das festas que tem expressão significativa para ser preservada é a UNESCO (United Nations Educational, Scientific and Cultural Organization/ Nações Unidas para a Educação, Ciência e Cultura). Ao ser reconhecido, um patrimônio passa a ser alvo de medidas que possibilitem sua maior valorização, transmissão, investimento e revitalização, constando neste processo a educação patrimonial formal e não formal (CABRAL, 2011).

Existem diferentes denominações para os tipos de patrimônio. Umas delas é que Michel Rautenberg (2003) faz quando distingue patrimônio por designação e patrimônio por apropriação. O primeiro faz alusão ao patrimônio formal, elitista, legitimado através de uma construção institucional. Já aquele por designação corresponde ao patrimônio 'não nobre', promotor do uso, cuja lógica social o constitui, como seria o caso das festas religiosas.

Na verdade, as festas religiosas proveniente dos santuários selecionados neste estudo, são patrimônios culturais imateriais, em potencial. Sua efemeridade (condição aparente) não rompe, nem se aparta de valor humanístico apenas "contabilizado" no plano simbólico (HOLZER, relacionando-se para fazer o momento da festa acontecer, gerando uma participação interativa e massiva, da comunidade local e de outros lugares, em uma movimentação turística religiosa e cultural (SANTOS, 2006; ALMEIDA, 2006; OLIVEIRA, 2010) ocasionada por estes eventos. Visando compreender o cerne da questão, foram aplicadas entrevistas com os docentes da Geografia escolar nas respectivas escolas. Ao checar os resultados, percebeu-se que a falta de informação dos alunos é em grande parte advinda do professor que por sua vez, alega a falta de materiais de apoio, condições de trabalho e ou a não obrigatoriedade curricular deste conteúdo como justificativa para ignorar tais abordagens.

A temática patrimonial carrega em si um desafio do desenvolvimento cultural. No século XXI temos visto uma propagação do conceito de patrimônio no sentido positivo e como necessário. Responsável por essa ascensão, temos o fator que atua de forma decisiva, a globalização.

A conjuntura histórica mostra que a tendência deste processo é a homogeneização dos costumes, crenças e hábitos. Em contrapartida, a patrimonialização emerge na tentativa de manter a diversidade cultural, reconhecendo-a e valorizando-a. Deste modo, o professor aparece como peça-chave neste processo, mesmo quando se diz respeito à festa em seu sentido religioso, pois:

\footnotetext{
O ensino religioso é um dos elementos da base nacional comum que visa à valorização do pluralismo e da diversidade cultural presente na sociedade brasileira. $\mathrm{O}$ conhecimento religioso enquanto patrimônio da humanidade deve estar à disposição na escola e promover oportunidades para os educandos se tornarem capazes de entender movimentos específicos das diversas culturas, cujo substantivo religioso só colabora no aprofundamento para a autêntica cidadania. (GIL FILHO, 2009, p. 26)
}

Trata-se de despertar a compreensão das imagens que compõem o cenário religioso. Pode partir do professor a abordagem dessa temática patrimonial-religiosa, prevista enquanto tema transversal, colocando em questão os símbolos que existem na sociedade e suas significações.

Através da abordagem religiosa, cultivar tolerância e construir a formação cidadã do aluno baseado na identidade e cultura, pois o preconceito, sobretudo o religioso, provém do fato de ser um tema pouco discutido e consequentemente pouco conhecido por parte dos alunos. Não se trata de proselitismos, mas do pensamento científico captando as percepções dos indivíduos para com os objetos, sua expressão no espaço e a efetivação de um novo pensar, perceber e proceder mediante a tais questões.

A festa religiosa nos santuários cearenses, portanto, mesmo percebida pelos sujeitos do ensinaraprender geografia, mantêm-se à margem do conteúdo geográfico do ensino médio; principalmente quando sua dimensão lúdica ou artística ganha autonomia frente às questões sociais e ambientais. Estas sim centrais neste campo de conhecimento (MACIEL, 2004). O que, despeito de toda sua potencialidade patrimonial para formação de interlocuções históricas e espaciais na compreensão cultural das localidades contemporâneas, não impede a recomposição do paradoxo imaginário

Geografia Ensino \& Pesquisa, v. 17, n.3, p. $127-142$, set./dez. 2013.

Oliveira, C. D.; Lima, F. J. L. A. P.; Carneiro, I. T.

ISSN 2236-4994 139 
constituído na representação educacional da festa. Se de um lado a marginalização do tema (objeto curricular) não pode ser ignorada, de outro, a demanda por representações como recriações da linguagem geográfica (RUIZ, 2004, 191-198) precisa aflorar como oportunidade de contextualização do saber advindo da religiosidade. Afinal, o problema não tem sido o silêncio tradicional da Geografia Escolar frente às múltiplas manifestações espaciais; mas a insensibilidade contextual quando tais manifestações cobram posturas curriculares (discussão, visita, simulação, apoio) aos valores patrimoniais do contexto local/regional.

\section{Concluindo}

O questionamento, que ainda no resumo inaugura a trajetória dessa pesquisa pode ser relembrado aqui, a título de apoio às sínteses conclusivas. Perguntávamos se os santuários cearenses projetam uma imagem de bens culturais e ambientais decisivos para a consolidação de uma Educação Patrimonial? Talvez a indagação sobre tais bens e fenômenos simbólicos servisse de "imagem decisiva", podendo sinalizar uma autocrítica para os termos que adotamos na problematização de um estudo. Uma imagem projetada na localidade - como festa de identidade e teor religioso e cultural - pode "decidir" adaptações do calendário escolar ou ações contextualizadas dos seus agentes, mediante uma negociação caso a caso.

Em geral, não é isto decide na realidade da escola pública os rumos do planejamento de conteúdos do ensino médio. Mesmo em eventos com maior volume de participantes (Romarias em Juazeiro do Norte, em Canindé ou Procissões dos bairros Fátima ou Vila Velha -Assunção, em Fortaleza), vamos constatar que a projeção dos atos devocionais pode forjar-se em "patrimônio", sem qualquer reivindicação dos ajustes do sistema escolar. Exatamente por isso, abrimos mão de auscultar na pesquisa um terceiro elemento social que corresponderia aos agentes organizadores das festas religiosas, a fim de saber como vêem a participação da escola nos próprios eventos. Afinal, em apenas um desses dez colégios encontramos um projeto pedagógico efetivamente articulado aos princípios da Educação Ambiental (E.E.M. Antonio Coelho, em São Benedito, conforme relato no final dos anexos), em confrmidade com os postulados de um projeto patrimonial associando escola-entorno local. E, por conseguinte, a projeção da imagem ficou restrita a uma espécie de avaliação pedagógica interna aos trabalhos da disciplina.

Nesse sentido, os santuários projetam sim uma possibilidade de desafiar a imaginação geográfica, no tocante às aulas de campo, em geografia especialmente. Eis o que todo esse levantamento indicou como base para os diálogos entre aulas mais contextualizadas com questões socioculturais da geografia e uma realidade complexa que não desconecta as festas de outras questões clássicas do saber geográfico: fluxos comerciais, desordem urbana, polaridades regionais, impactos ambientais, controles sanitários, abastecimento, regimes do tempo climático, etc. $\mathrm{O}$ desafio vem a ser colocar o estudante em condição de visitação, permitindo que seu processo de educação patrimonial absorva progressivamente, de um lado, o sentimento dos turistas religiosos (ou peregrinos pós-modernos); e de outro, a racionalidade dos pesquisadores em campo.

As aulas de campo, na maioria das vezes ignoram as "aulas" fomentadas pelas outras formas de participação no campo (ou no entorno). Mas a vivência dos alunos - ainda que estejam por moradia ou confissão religiosa distanciados dessas festividades - indica sua participação nesse tipo de aula. Como resultado dessa constatação, foi possível recolher depoimentos de docentes, cuja experiência não envolve, na escola, nenhum trabalho sistemático com as festas. Muito embora não

Geografia Ensino \& Pesquisa, v. 17, n.3 p. 127-142, set./dez. 2013

Representações do patrimônio na Geografia escolar: o imaginário da festa religiosa cearense no ensino médio demonstrem qualquer resistência a possibilidade de iniciar um trabalho desse tipo com os conteúdos geográficos mais adequados. Primeiro por que todos mostraram fluência no conhecimento de dois ou mais santuários (e festas), dada sua própria vivência cultural ou religiosa. Depois pela rápida constatação de que um trabalho dessa natureza (centrado na temática da festa religiosa como bem patrimonial) permitiria sim interessantes conexões com questões político-econômicas e ambientais na implementação de uma aprendizagem sobre a formação geográfica do local e região. Casos 
como a devoção do Olho D'água da Bica, em Tabuleiro do Norte, do Menino Jesus de Praga em Chorozinho e N. S. Rainha do Sertão em Quixadá são exemplares, na preocupação docente, com o aproveitamento da festa para discussão dos mananciais hídricos dos rios Jaguaribe, Chorozinho e Quixadá, por exemplo. Já nos casos da capital Fortaleza e Caucaia o destaque do imaginário docente direcionou-se às questões de infraestrutura urbana (segurança, transporte, saúde), seja para demonstrar as ausências do poder público em tais questões, seja para mostrar as desigualdades no tratamento cultural de eventos sociais, afinal o catolicismo permanece em uma posição de destaque para os gestores e comerciantes aferirem votos e consumidores.

Tanto em uma situação (mais colaborativa), como em outra (mais crítica) a educação patrimonial é fundamentalmente potencialidade na reestruturação curricular de aulas de campo. Cabe, portanto, a estudos que deem continuidade a investigação do imaginário docente da festa, como estratégia de representação do patrimônio, um acompanhamento centrado em casos específicos. Provavelmente mais centrados em estudos comparativos de casos que lidem diretamente com projetos de Educação Patrimonial em vias de consolidação. O que permitiria, por exemplo, a avaliação em profundidade da escola de São Benedito; e não apenas na comparação de uma amostragem regional, sem a inclusão de particularidades especificas da relação entre a escola, o santuário e os projetos educacionais.

Sendo assim, para a inclusão da Educação Patrimonial, nos percursos da Geografia Escolar que o Ensino Médio contemporâneo demanda - crescentemente articulado às exigências da interdisciplinaridade do eixo Ciências Humanas e Sociais - faz-se urgente apresentar os resultados desse projeto (via site, artigos e programas) no apoio a tais aprofundamentos. O que não elimina novas indagações sobre a formação da resistência do geógrafo educador no tratamento de temas culturais.

\section{Referências}

ALMEIDA, Maria Geralda de. Cultura, turismo e identidade. In: SILVA, José B.; lima, Luis Cruz; ELIAS, Denise (orgs.). Panorama da Geografia brasileira 1. São Paulo: Annablume, 2006. . p109-122.

AMARAL, Rita. As mediações culturais da festa à brasileira. In: TAE - Trabalhos de Antropologia e Etnologia. Revista inter e intradisciplinar de Ciências Sociais, vol. 40 (1-2). Sociedade Portuguesa de Antropologia e Etnologia, Porto, 2000

BACHELARD, G. A Formação do Espírito Científico. São Paulo: Contraponto, 2008.

BECKER, Howard. Segredos e Truques da Pesquisa. Rio de Janeiro: Zahar, 2007.

CABRAL, C. B. Património Cultural Imaterial: convenção da UNESCO e seus contextos. Lisboa: Arte\&Comunicação 98, 2011.

CASTRO, Iná Elias. Do imaginário tropical a política: a resposta da geografia brasileira à história da maldição. Scripta Nova Revista Electrónica de Geografía y Ciencias Sociales. Universidad de Barcelona. ISSN: 1138-9788. Depósito Legal: B. 21.741-98 Vol. X, núm. 218 (11), 1 de agosto de 2006.

CLAVAL, Paul. Geografia Cultural. Florianópolis. UFSC. 1999.

CUENCA, J.M. El patrimonio en la Didáctica de las Ciencias Sociales: Concepciones, dificultades y obstáculos para su integración en la enseñanza obligatoria. Tesis doctoral. UHU, 2002.

DARDEL, Eric. O Homem e A Terra. Natureza da realidade geográfica. São Paulo: Ed Perspectiva, 2011.

DI MEO, Guy. Le sens géographique des fêtes. In: Annales de Géographie. 2001, t. 110, nº622. P. 624-646. Disponível em <http://www.persee.fr /web/revues/home/prescript/article/> Acesso em 24 de fev. de 2013

ESPINA BARRIO Angel; MOTTA Antonio, GOMES Mario H. (orgs.). Inovação Cultural, Patrimônio e Educação.Centro de Estudios Brasileños. USAL. 2005. Disponível em <http:// campus.usal.es/ iiacyl/MAI/images/publicaciones/livro\%20> Acesso em 12 de dez./2012

ESTEPA, J.; DOMÍNGUEZ, C; CUENCA, J.M. La enseñanza de valores a través del patrimonio in: Los valores y la Didáctica de las Ciencias Sociales. Zaragoza, Universidad de Lleida- AUPDCS, 1998.

Geografia Ensino \& Pesquisa, v. 17, n.3, p. $127-142$, set./dez. 2013.

Oliveira, C. D.; Lima, F. J. L. A. P.; Carneiro, I. T.

ISSN 2236-4994 | 141 
FERRARA, Lucrécia. D’A. Comunicação, Espaço e Cultura. São Paulo, Annablume, 2008.

FONTAL MERILLAS, Olaia. La educación patrimonial: teoría y práctica en el aula, el museo e internet. Gijón, Ediciones Trea SL, 2003.

GRUNBERG, Evelina. Manual de atividades práticas de educação patrimonial Brasilia-DF:IPHAN, 2007.

HERVIEU-LERGER, Daniele. O peregrino e o convertido: a religião em movimento. Petrópolis: Ed. Vozes, 2008

HOLZER, W. A. Geografia Cultural e a História: Uma Leitura a partir da Obra de David Lowenthal. in Espaço e Cultura, Uerj, RJ, nº. 19-20, p. 23-32, jan./dez. de 2005.

HORTA, Mª de Lourdes Pereira. Memória, Patrimônio e Identidade. Ministério da Educação. 2005.

JUNQUEIRA, S. (Orgs). O sagrado: fundamentos e conteúdos do ensino religioso. Curitiba: Ibpex, 2009.

LICERAS RUIZ, Ángel. Dificultades en el Aprendizaje de las Ciencias Sociales: Una perspectiva psicopedagógica. Granada: Grupo Editorial Universitario, 1997.

MACIEL,Caio Augusto A. Metonímias geográficas: imaginação e retórica da paisagem do semiárido pernambucano. Anu. Inst. Geocienc., 2004, vol.27, p.100-101. ISSN 0101-9759.

MARTINS, Heloisa Helena T. de Souza. Metodologia qualitativa da pesquisa. Disponível em < http://www.scielo.br/pdf/ep/v30n2/v30n2a07.pdf> Acesso em 28 de fev/2013.

MATTOZZI, I. La didáctica de los bienes patrimoniales: a la búsqueda de una definición. In: ESTEPA GIMÉNEZ, J; DOMINGUEZ, C; CUENCA LÓPEZ, J. M.. Museo y Patrimonio en la didáctica de las Ciencias Sociales. Huelva, Universidad de Huelva. 2001

OLIVEIRA, Christian D. M. de. Sentidos da Geografia Escolar. Fortaleza, Edufc, 2010.

PAIVA, Rita. Gaston Bachelard. A Imaginação na Ciência, na Poética e na Sociologia. São Paulo: Annablume. Fapesp, 2005.

PELEGRINI, Sandra C. A. Patrimônio Cultural: Consciência e Preservação. São Paulo: Brasiliense, 2011

POULOT, D. Uma história do patrimônio no Ocidente, séculos XVIII-XXI: do monumento aos valores. São Paulo: Estação Liberdade, 2009.

QUEROL, María A. Manual de Gestión del Patrimonio Cultural. Madrid: Akal textos, 2010. RAUTENBERG, Mi. La Rupture Patrimoniale. Paris A LA CROISEE Coleção: Ambiance Ambiance, 2003.

REZENDE, A. M. Uma concepção fenomenológica da Educação. São Paulo, Cortez, 1990.

ROSENDHAL, Zeny. O sagrado e o urbano: gênese e função das cidades. In Espaço e Cultura. Rio de Janeiro: EdUERJ / NEPEC. 1996.

RUIZ, Castor M. M. Bartolomé. Os Paradoxos do Imaginário. São Leopoldo, Ed. Unisinos. 2004.

SÁ, Celso Pereira de. Núcleo Central das Representações Sociais. Petrópolis. Vozes. 2002.

SANTOS, Maria G. M. P.. Espiritualidade, Turismo e Território: estudo geográfico de Fátima. ed. 1, ISBN: 972-8818-76-9. Lisboa: Principia, 2006.

TRIVINHO, Eugenio. A dromocracia cibercultural: Lógica da vida humana na civilização mediática avançada. São Paulo: Paulus, 2007.

VICENT BOIRA, Josep; REQUES, Pedro; MANUEL SOUTO, Xosé. Espacio Subjetivo y Geografía: Orientación teórica y praxis didáctica. Valencia: Nau Libres, 1994.

\section{Correspondência:}

Christian Dennys Oliveira - Universidade Federal do Ceará, Departamento de Geografia. Campus do Pici - Bloco 911. CEP 60455760, Fortaleza, CE - Brasil.

Geografia Ensino \& Pesquisa, v. 17 n. 3 p. $127-142$, set./dez. 2013

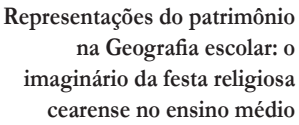
na Geografia escolar: 0 imaginário da festa religiosa cearense no ensino médio

E-mail: cdennys@gmail.com

Recebido em 29 de outubro de 2012.

Revisado pelo autor em 03 março de 2013.

Aceito para publicação em 06 de março de 2013. 